\title{
INDÚSTRIA DE DEFESA E DESENVOLVIMENTO: CONTROVÉRSIAS TEÓRICAS E IMPLICAÇÕES EM POLÍTICA INDUSTRIAL
}

\section{Christiano Cruz Ambros ${ }^{1}$}

\section{Introdução}

Duas discussões principais permeiam a relação entre defesa e desenvolvimento: i) se há relação entre gastos militares e crescimento econômico; e ii) se os gastos militares geram desenvolvimento tecnológico na sociedade como um todo. Estas duas discussões são basilares tanto para as motivações e justificativas utilizadas pelos atores políticos para gastos militares quanto para as políticas públicas (inclusive as políticas industriais) voltadas para o setor de defesa.

Em sua obra de referência para a economia da defesa, Hartley e Sandler (I995, 20I-20I5) fazem uma importante revisão da literatura especializada no debate entre defesa e desenvolvimento dentro de diversas escolas de pensamento econômico. Para os autores, os principais estudos que encontram correlações positivas entre gastos militares e desenvolvimento econômico apresentam cinco pontos principais: I) efeito de estímulo econômico dos gastos militares durante períodos de desemprego, causados tanto pelo subconsumo quanto por subinvestimento; 2) efeitos tecnológicos e de spin-offs do setor que defesa que, quando aplicados ao setor civil, causam crescimento econômico; 3) gastos militares podem aumentar o crescimento se alguns destes gastos forem utilizados para prover infraestrutura social (como barragens, rodovias, aeroportos, redes de comunicação) e outras formas de

\footnotetext{
I Doutor em Ciência Política pela Universidade Federal do Rio Grande do Sul (UFRGS). Atualmente é Analista Internacional na Secretaria do Desenvolvimento Econômico, Ciência e Tecnologia do Governo do Estado do Rio Grande do Sul. E-mail: chrisambros@gmail.com
} 
bens públicos; 4) gastos militares podem promover o crescimento ao prover nutrição, treinamento e educação a um segmento da população, e este capital humano aprimorado pode impactar positivamente no setor civil; e 5) os gastos militares podem indiretamente apoiar um ambiente seguro para a promoção de um mercado exportador e para a atração de investimentos estrangeiros.

Para os autores (Ibid., 202), aqueles que consideram que as atividades de defesa podem ter uma influência inibidora no crescimento argumentam que: I) a defesa pode desviar recursos de investimentos públicos e privados que seriam mais fomentadores de crescimento do que a defesa, dado que se a defesa competir por recursos intencionados para o investimento privado, então qualquer efeito de deslocamento (crowding-out) irá ter impactos negativos no crescimento econômico de longo-prazo; 2) se um país importa grande parte dos seus armamentos, os gastos militares podem ter impactos adversos na balança de pagamentos; 3) o crescimento econômico pode ser inibido quando as atividades de defesa desviam recursos de pesquisa e desenvolvimento (P\&D) do setor privado, pois ainda que possam existir spin-offs tecnológicos, as aplicações de tecnologias para o setor privado geralmente são mais rápidas e mais direcionadas se elas são originadas pelo próprio setor privado; 4) os gastos militares podem inibir o crescimento ao desviar recursos originalmente destinados ao setor exportador, fazendo com que mercadorias que trariam divisas para o país não sejam vendidas no exterior; e 5) o setor de defesa limita o crescimento através de burocracias ineficientes e amarras criadas por impostos utilizados para financiar os gastos militares, assim como o setor público em geral.

Neste exercício de reflexão, iremos discutir contribuições que utilizam abordagens clássicas, marxistas, neoclássicas e keynesianas de desenvolvimento para expor os debates em relação aos gastos militares e crescimento econômico, e, por outro lado, trataremos da contextualização da Indústria de Defesa como fator impulsionador do desenvolvimento tecnológico e da inovação utilizando-nos das teorias cepalinas e schumpeterianas, além de abordagens sistêmicas sobre as transições técnico-econômicas históricas do sistema internacional. Conforme argumentaremos, a contribuição da Indústria de Defesa para o desenvolvimento vai além da concepção de relação causal entre gastos militares e crescimento econômico, sendo um setor capaz de endogeneizar determinadas tecnologias e processos produtivos que estruturam a capacidade de um país orientar sua trajetória de desenvolvimento em novos paradigmas técnico-econômicos. Para o Estado perseguir a estratégia de nacionalização de tecnologias críticas desses novos paradigmas, são necessários arranjos institucionais e instrumentos articulados com uma política industrial coerente e robusta. 


\section{Gastos Militares e Crescimento Econômico}

Geralmente, para a teoria econômica não há distinção clara entre gastos públicos gerais e os gastos militares. Estes tratam-se somente de outra forma de gastos governamentais. Resumida e superficialmente, podemos dizer que, para a teoria neoclássica, a segurança pode até ser necessária ao comércio, mas haverá um custo de oportunidade (trade-off) entre "armas e manteiga" ${ }^{2}$, enquanto para os keynesianos, a segurança, dado constituir-se em gasto público, pode ter efeitos positivos na demanda (Dunne e Haines 2000). Para os marxistas, em partes combinam-se as duas visões, mas os estudiosos da corrente do Subconsumo veem um claro e positivo papel nos gastos militares, ainda que não tenham encontrado comprovações empíricas que sustentem tal visão (Smith e Dunne I994). Segundo Dunne e Nikolaidou (20II), a análise econômica dos gastos militares é extremamente difícil na medida em que não se trata de um assunto puramente econômico, mas uma mistura de fatores econômicos, políticos, estratégicos, psicológicos, culturais e até mesmo morais.

Adam Smith (I723-I790) foi o primeiro grande economista a defender o livre mercado como regra essencial para o bom funcionamento da economia e a postular que o Estado deve interferir o mínimo possível na relação entre o poder e o mercado. Entretanto, Smith postula sobre o caráter especial da defesa e a importância do monopólio da força estar exclusivamente nas mãos do soberano. Matthews e Maharani (2009, 9I) colocam que Smith tinha uma visão da defesa como o bem público por definição, que era importante demais para ser deixado para o mercado. Segundo os autores,

a insistência de Smith no domínio da defesa pelo setor público tem duas justificativas: primeiramente, a defesa representa um dos melhores exemplos do ótimo de Pareto, isto é, onde todos os cidadãos se beneficiam da provisão de um bem sem o perigo do "free-riding"; e segundo, a política deve ser orientada para que as iniciativas em produtos de defesa sejam públicas, pois apenas a propriedade pública irá garantir a soberania da oferta continua às partes interessadas (Matthews e Maharani 2009, 9I).

\footnotetext{
2 Skinner (1969) introduziu um conceito fundamental no estudo de estratégia e gerência de operações: os trade-offs. Um trade-off é definido como uma situação em que há conflito de escolha, ou seja, o balanceamento de duas situações ou qualidades opostas, que são desejadas concomitantemente. Por exemplo, um trade-off clássico se dá entre "armas e manteiga", quanto mais gastamos em defesa nacional (armas) para proteger nossas fronteiras de agressores estrangeiros, menos podemos gastar com bens de consumo (manteiga) para elevar nosso padrão de vida interno.
} 
Adam Smith defendia que os gastos com defesa devem ser obrigação do Estado soberano, inclusive para a manutenção de um exército permanente e profissional, seguindo sua própria lógica da divisão do trabalho em uma sociedade. Além disso, aceitando a importância da produção material para a soberania da nação, Smith admitia que interferências do Estado na economia, em especial em relação às restrições de importações, são admissíveis quando servem para proteger as indústrias essenciais à defesa nacional. Nesse sentido, Smith defendia a manutenção dos Atos de Navegação do Reino Unido, ainda que fossem desfavoráveis ao comércio exterior a partir do aumento de custos. Dado que a marinha mercante era facilmente convertida em marinha de guerra, tornava-se um requisito estratégico sustentar a indústria naval britânica em tempos de paz para garantir sua existência em tempos de guerra. Portanto, Smith não necessariamente discutia o impacto dos gastos militares no crescimento econômico, mas via a indústria de defesa como estratégica para o poder das nações.

$\mathrm{Na}$ abordagem Marxista, o fenômeno da guerra é muitas vezes visto como um instrumento para a destruição do estoque de capital, que em excesso prejudica a taxa de lucro dada a composição orgânica do capital. Ou seja, a guerra seria uma forma de o sistema capitalista continuar o seu processo contínuo de acumulação a partir da destruição de estoque de capital constante que não são mais suficientemente produtivos. Dunnes $(2000,6)$ aponta que Baran e Sweezy (1966), marxistas teóricos do subconsumo, foram um dos primeiros autores a refletir de fato sobre os mecanismos dos gastos militares como forma de beneficiar o crescimento da taxa de lucro capitalista quando a economia está em desequilíbrio. De maneira geral, os marxistas tendem a considerar o militarismo e os gastos militares como fenômenos sociais dentro de aspectos históricos e focam nos aspectos estratégicos e políticos dos gastos militares.

A teoria Keynesiana do crescimento econômico reflete o delicado período da economia internacional das décadas de I920 e I930, introduzindo pela primeira vez no debate conceitos macroeconômicos. A preocupação central de Keynes em relação ao crescimento econômico é com a dinâmica da demanda efetiva da economia, pois, dado que a oferta tende a se ajustar à demanda efetiva no longo prazo, acaba que o consumo e o investimento determinam o produto e o emprego em uma economia. Assim, segundo Porcile, Esteves e Scatolin (2006, 365), "o governo, para diminuir o desemprego, pode aumentar a demanda efetiva via aumento do gasto público, levando a um aumento do produto". Na visão de estado intervencionista e proativo de Keynes, os gastos militares poderiam ser utilizados para aumentar o produto a partir de efeitos multiplicadores quando a demanda agregada é ineficiente. 
Além disso, se a demanda agregada é relativamente baixa em relação à oferta potencial, os aumentos dos gastos podem levar ao aumento da capacidade produtiva utilizada, aumentando lucros e, portanto, aumentar investimentos e crescimento econômico.

Segundo Dunne e Nikolaidou (20II), os modelos keynesianos de demanda são amplamente utilizados para explicar a relação entre gastos militares e crescimento econômico, que, em geral, tendem a encontrar uma relação negativa entre gastos militares e crescimento econômico, verificando o Efeito de Deslocamento (Crowding out) de poupanças ou investimentos. A relação direta entre aumento dos gastos militares e crescimento econômico na lógica keynesiana encontra um desafio básico que é depender-se de uma base industrial de defesa nacional para que as despesas militares não sejam revertidas em importações. Além disso, para os autores, a desvantagem básica dessa teoria é o foco excessivo na demanda e as falhas em considerar as questões relativas à oferta dos produtos de defesa (desenvolvimentos tecnológicos e externalidades positivas).

A Escola Neoclássica tende a perceber os gastos militares como um bem público puro e os efeitos econômicos desses gastos serão determinados pelos seus custos de oportunidade, ou seja, o trade-off entre gastos militares e algum outro gasto. Esta abordagem percebe o Estado como um ator racional que procura equilibrar os custos de oportunidade e os benefícios da segurança obtida com os gastos militares para maximizar um interesse nacional bem definido e refletido em uma função de bem-estar social (Dunne 2000).

Graças à tendência a ocorrer uma escolha trágica entre gastos militares e outros gastos, bem exemplificado no clássico dilema "armas e manteiga”, os neoclássicos geralmente defendem que gastos em defesa deterioram o crescimento econômico. Essa correlação negativa entre gastos militares e crescimento econômico é observada por Tekeoglu (20II) nos trabalhos de Deger (I986), Deger \& Smith (I983), Heo (I999), Kwaben (I989), Lim (1983) e Shieh (2002). Para Dunnes (2000), os modelos neoclássicos mais influentes na economia da defesa são os de Biswas e Ram (I986), desenvolvidos a partir do modelo de Feder (I982). Com o modelo de Feder sobre efeitos das exportações no crescimento de países em desenvolvimento, estes autores criaram um modelo para análise entre países sobre o efeito dos gastos militares no crescimento econômico. Os modelos baseados em Feder tendem a sugerir que os impactos dos gastos militares no crescimento são positivos, especialmente a partir dos efeitos da exportação e transferência tecnológica, ou são insignificantes (Dreze 2006). 
O modelo econômico aumentado de Solow ${ }^{3}$, introduzido por Mankiw em I992, foi utilizado para mensurar os efeitos dos gastos militares no crescimento por Knight et al. (I996). A premissa chave é de que a porção do gasto militar afeta o fator da produtividade através do nível de efeito no parâmetro de eficiência que controla o aumento do trabalho dada a mudança tecnológica. Ou seja, o principal efeito dos gastos militares na economia é o incremento da tecnologia.

Os modelos neoclássicos para a análise de gastos militares e seus impactos no crescimento econômico têm a vantagem de permitir o desenvolvimento de modelos formais consistentes para análises empíricas. Entretanto, em geral, a escola fornece modelos de eficiência alocativa estática, que são visivelmente limitados por não considerarem aspectos históricos e dinâmicos, além de concentrarem-se excessivamente no lado da oferta, "ignorando o papel interno das Forças Armadas e de seus interesses, supondo a existência de um consenso nacional e exigindo conhecimento extremo e habilidades cognitivas irreais dos atores racionais" (Dunnes 2000, 5).

Em uma importante e provocativa contribuição, Emile Benoit (I973) apontou para uma associação positiva entre gastos militares e crescimento econômico para quarenta e quatro países em desenvolvimento durante o período de I950-65. Nestes casos, os maiores gastos com defesa como uma proporção ao Produto Interno Bruto (PIB) podem ter promovido o crescimento econômico (medido pelo crescimento da produção de produtos civis) para esses países. Segundo Hartley e Sandler (I995), os polêmicos estudos de Emile

3 O Modelo de Solow é um dos principais estudos estruturantes da escola neoclássica. Nele, além da concorrência perfeita, os fatores de produção são homogêneos, divisíveis e perfeitamente substituíveis entre si (ou seja, um dos principais pressupostos neoclássicos). O modelo procura relacionar a poupança, a acumulação de capital e o crescimento demográfico (que automaticamente se torna o mercado de trabalho) para explicar a variação do produto per capita no longo prazo. O aprofundamento do capital, ou seja, sua acumulação (em uma linguagem marxista), é financiado pela poupança per capita, que deve ser suficiente para fornecer capital à população que cresce a um determinado ritmo e para depreciar o capital existente. Segundo Souza (20II, 264), "a conclusão do modelo é a de que a elevação da taxa de poupança expande a relação K/L e a renda per capita até a economia atingir o equilíbrio estável de longo prazo, quando a taxa de crescimento do produto per capita manter-se-á constante e igual à taxa de crescimento da população". Entretanto, uma vez que o equilíbrio é atingido, o aumento da poupança não impactará mais na taxa de crescimento do produto a ponto de elevá-la acima da taxa do crescimento demográfico. Ou seja, a explicação do crescimento a longo prazo é exógena ao modelo de Solow, que introduz o progresso tecnológico como variável exógena explicativa do crescimento sustentável a longo prazo, pois é o aumento da técnica que proporcionará maior produtividade do trabalho e maiores taxas de aprofundamento do capital. Finalmente, Souza (ibidem, 265) conclui que "a importante conclusão do modelo neoclássico é a de que o ritmo do progresso técnico determina o crescimento da renda per capita no equilíbrio estável de longo prazo". 
Indústria de Defesa e Desenvolvimento: controvérsias teórias e implicações em política industrial

Benoit suscitaram pesquisas com as mais diferentes abordagens teóricas da economia buscando encontrar falhas na sua metodologia ou aplicar outros modelos analíticos para estudar os mesmos casos.

Resumidamente, estes modelos eram focados no lado da oferta ${ }^{4}$, no lado da demanda5, ou uma combinação de ambos. Hartley e Sandler (I995, 20I5) colocam que a maioria dos modelos focados no lado da demanda encontraram impactos negativos dos gastos militares no crescimento econômico dada a competição dos recursos em defesa com outros investimentos. Os principais estudos que corroboram estas análises são Deger (I986), Deger e Smith (I983), Lebovic e Ishaq (I987) e Scheetz (I991). Entretanto, quando a abordagem do lado da oferta é empregada, os gastos militares podem ter influência positiva a partir de spin-offs e externalidades positivas. Mais que isso, em estudos com países em desenvolvimento, os efeitos em produtividade foram positivos. De forma geral, os estudos do lado da oferta encontram que os gastos militares têm um pequeno efeito positivo ou quase nenhum efeito de externalidade do crescimento econômico.

Conforme colocam Hartley e Sandler (1995, 2020), ainda que estudos individuais do impacto dos gastos militares no crescimento econômico tenham resultados aparentemente controversos, ainda é possível verificar algumas fortes consistências. Enquanto modelos baseados na demanda tendem a verificar o fenômeno do deslocamento de recursos (crowd out) e o impacto negativo no crescimento, os modelos do lado da oferta quase sempre demonstram um impacto positivo ou neutro. Assim, não se pode confirmar a relação positiva ou negativa entre crescimento econômico e gastos militares. Entretanto, demonstra-se que a tecnologia envolvida nos processos das empresas relacionadas à defesa pode contribuir para o desenvolvimento de um país. Por isso, na próxima seção focaremos no debate sobre a relação entre tecnologias militares e civis na dinâmica do desenvolvimento tecnológico de um país.

4 Ver em Hartley e Sandler (I995, 204-2009) que as explicações focadas no lado da oferta da relação entre defesa e crescimento econômico derivam da função de produção agregada. Do nível mais macro, a renda nacional ou produção, Y, pode ser expressa como uma função de recursos e tecnologia $-\mathrm{Y}=\mathrm{F}(\mathrm{L}, \mathrm{K}, \mathrm{Tc})$, onde $\mathrm{L}$ é o trabalho agregado, $\mathrm{K}$ é o capital agregado, e Tc é o índice de tecnologia (Deger e Smith I983). A partir dessa equação básica, modelos (Mueller e Atesoglu I993) estudaram cenários da tecnologia militar incorporada ou não nos recursos disponíveis e focaram no estudo das produtividades diferenciadas e das redes de externalidades entre setor privado, setor público não militar e setor militar (Ferder I983; Ram I986; Biswas e Ram I986).

5 Os modelos do lado da demanda baseiam-se nas representações de Keynes da demanda agregada, onde a renda, Y, ou produção potencial em pleno emprego, Q, é a soma de componentes da demanda real por produtos e serviços, ou seja: $\mathrm{Y}=\mathrm{Q}-\mathrm{W}=\mathrm{C}+\mathrm{I}+\mathrm{M}+\mathrm{B}$, onde $\mathrm{W}$ é a lacuna entre a produção atual e a potencial, C é o consumo agregado, I é o investimento público e privado, M são os gastos militares reais, e B é a balança comercial. Alguns modelos são aplicados por Deger (I986), Faini, Annez e Taylor (I984) e Lebovic e Ishaq (I987). 


\section{Gastos militares e Desenvolvimento Tecnológico}

É importante distinguir entre os tipos de gastos militares e seus impactos. Dumas (2004) coloca que os gastos militares são um conceito amplo, que pode ser divido em Operações e Manutenção, que inclui o pagamento e o suporte operacional dos militares que servem as Forças Armadas; e Aquisição, que inclui as compras de sistemas de armas produzidos domesticamente ou no exterior e serviços de P\&D. Ambos os tipos de gastos consomem capital financeiro, mas a aquisição tem um efeito muito maior na alocação de ativos chaves de trabalho industrial e tecnológico e capital físico (Dumas 2004, 23). É a partir dos projetos concebidos para aquisições militares que os efeitos de spill-over, spin-offe spin-on supostamente ocorreriam.

Bohn (20I4) coloca que os termos spill-over e spin-off são muitas vezes utilizados intercambiavelmente de maneira equivocada. De maneira sintetizada, o termo spill-over (que teria como tradução literal "transbordamento") trata das externalidades gerais de projetos militares, enquanto spin-off seria especificamente o transbordamento dos resultados tecnológicos advindos do setor militar para o setor civil da economia, e spin-on seria o caminho inverso, ou seja, tecnologias civis sendo convertidas para fins militares.

Conforme aponta Walsh (2009), a concepção de que processos de spill-over e spin-off ocorreriam a partir dos investimentos públicos no setor de defesa se iniciou nos EUA após a Segunda Guerra Mundial. Entre os exemplos frequentemente apontados como spin-off em termos gerais estão o uso da energia nuclear, a tecnologia espacial para comunicações, meteorologia e criptografia, além de produtos propriamente ditos como o radar, o transistor, o forno de micro-ondas, a cobertura Teflon, o GPS, o raio laser medicinal, a internet e o telefone celular.

Ainda que os processos de spin-off, spill-over e dualização de tecnologias sejam defendidos como modelos de desenvolvimento e sustentação da indústria de defesa de diversos países (Walsh 2009), autores como Dagnino (20IO) apontam que eles são utilizados como elementos de uma construção ideológica para defender gastos militares exacerbados que não encontram sustentação em estudos acadêmicos. Ou seja, a ideia de spin-off - que, segundo o autor (2010, I53), foi um fenômeno real e observável no pós-Segunda Guerra -, logo se transformou no paradigma do spin-off, que se constitui numa ideologia concebida e utilizada pelos EUA para justificar e promover o dispêndio de vultuosos recursos para P\&D militar necessários para o enfrentamento latente com a União Soviética. Segundo coloca Dagnino (2010, I03), 
divulgada pelo establishment dos países centrais, mas criticada por eminentes cientistas e por setores da sociedade, a ideia do spin-off foi alvo de um intenso debate nas instituições acadêmicas, militares e nas instâncias de tomada de decisão governamental desses países (...) estudos realizados nos países avançados, mesmo seguindo diferentes enfoques disciplinares, têm mostrado implicações indesejáveis de P\&D militar para o sistema de pesquisa civil. Com um enfoque macroeconômico e temporal, alguns deles têm chamado atenção, mediante pesquisa empíricas comparando séries temporais de despesas em P\&D militar e de orçamento público para pesquisa, que o primeiro não tem se comportado como uma variável aditiva e sim como um gasto que tende a ser deduzido do montante total aplicado.

Assim, Dagnino (20I0) aponta que é bastante controversa a ideia de que os spin-offs da produção de sistemas de armas gerariam benefícios econômicos e sociais, assim como a crença de que a difusão das tecnologias produzidas no meio militar para o setor civil seria um fluxo natural e que seria possível adaptá-las com esforço mínimo para aplicações na indústria civil. Diante desta concepção, justificar gastos militares com base em ganhos econômicos e tecnológicos seria inviável.

Consideramos que os processos de spill-over, spinon e spin off não são automáticos e não seguem um fluxo natural. Precisam ser estimulados por políticas que levem em consideração questões como propriedade intelectual, financiamento, capacidade de absorção tecnológica e potencial de comercialização de produtos. Além disso, de maneira geral, os ganhos em desenvolvimento tecnológico não necessariamente estão na conversão do produto final de P\&D militar em aplicações civis, mas sim em todo o processo de pesquisa básica e aplicada e capacitação de uma cadeia de fornecimento de componentes e subcomponentes que foi necessária para criar o produto final.

A separação entre tecnologias civis e militares não é tão clara quando observamos seu processo de concepção e de desenvolvimento, e não somente sua aplicação. É comum imaginar as revoluções nas tecnologias militares como processos independentes da sociedade, de alguma forma separáveis da atividade humana de esferas não-militares. Existe valor analítico ao se assumir que há um setor militar definido na sociedade, mas muito mais pode ser aproveitado se pensarmos em termos das ligações fundamentais e extensivas que conectam esse setor à tecnologia do setor civil. Apesar dos seus elementos distintivos, as mudanças frequentes nas tecnologias militares precisam ser vistas não como algo separado, mas sim como um elemento integrante de uma revolução ampla na ciência, tecnologia, e condição humana como um todo devido à emergência da idade industrial, e agora da idade da tecnologia da informação (Buzan e Herring I998). 
Buzan e Herring $(1998$, 2I) colocam que em todas as eras, tecnologias civis e militares estiveram bem próximas. A proximidade das tecnologias civis e militares durante o século XIX é evidente tanto em termos do corpo de conhecimento comum que as fundamenta quanto as numerosas sobreposições entre as aplicações civis e militares dessas tecnologias. Durante o século XIX, o conhecimento da metalurgia, das técnicas de engenharia e de design que gerou a revolução nas armas de fogo foi o mesmo conhecimento que produziu cada vez mais eficientes motores a vapor para mineração, navegação, máquinas ferroviárias, e a indústria do setor civil. De maneira similar, o conhecimento em química que desenvolveu explosivos mais eficientes também está intimamente ligado com o conhecimento que sustentava a indústria florescente de químicos ligados a fins civis, indo desde fertilizantes a farmacêuticos. Nestes dois casos, assim como em muitos outros, o conhecimento e as habilidades que produziram revoluções nas tecnologias militares foram quase indistinguíveis daquelas que serviram para fins civis.

Atualmente, o advento da digitalização ${ }^{6}$ em larga escala tende a borrar ainda mais a fronteira entre tecnologias militares e civis. Geralmente, na área militar a digitalização é denominada Revolução em Assuntos Militares (RAM), abordando a incorporação de tecnologias da comunicação e informação e o avanço da consciência situacional nas esferas da estratégia, da operação e da tática. Entretanto, Martins $(2008,7)$ crítica a denominação da RAM por focar demasiadamente no confronto entre exércitos, e não entre sociedades. Ou seja, por separar de maneira clara o setor militar do civil. Conforme Martins (2008, 7-8),

se considerarmos a definição de Clausewitz, para o qual a guerra é um confronto entre sociedades e não apenas entre exércitos, esta terminologia usual (RMA) fica anacrônica. A ideia de se falar em uma revolução apenas em "assuntos militares" perde a dimensão dos impactos da digitalização na economia civil, que se reflete na confluência tecnológica entre a televisão, o telefone e o computador, que passam a operar em uma mesma rede e em uma base de hardware comum. A mudança trouxe novos padrões para a produção material, para a administração de empresas e para a alavancagem e financiamento de negócios. Daí o uso do termo digitalização (em vez de RMA), mais simples e preciso, para dar conta do caráter sistêmico da mudança em curso.

6 Conforme coloca Martins (2008, 7), “digitalização é o processo pelo qual um determinado dado (imagem, som, texto) é convertido para o formato binário para ser processado por um computador. No plano militar, a digitalização diz respeito à confluência entre o radar, o infravermelho, o laser e as micro-ondas de alta potência". 
A concepção de que o processo de desenvolvimento tecnológico militar e civil são mais próximos do que aparentam é relevante para se compreender o papel dos gastos militares em revoluções tecnológicas que influenciam no desenvolvimento econômico. A ideia de processos evolucionários e revoluções tecnológicas é introduzida no pensamento teórico sobre crescimento econômico por Joseph Schumpeter (I96I). Na visão schumpeteriana, a mudança tecnológica é o elemento central da dinâmica capitalista e o nível microeconômico, ou seja, da firma, estaria no centro deste processo de inovação. O fenômeno do desenvolvimento é mais revolucionário que incremental, na medida em que os ciclos econômicos são alterados de uma vez por todas pelas inovações e tecnologias introduzidas. Diferentemente da visão neoclássica, Schumpeter alega que o desenvolvimento impulsionado por novas tecnologias não gera impactos uniformes nos resultados operacionais e nem são fatores produtivos facilmente absorvidos por todos os atores envolvidos no mercado. Ou seja, a tecnologia cria desigualdades e hierarquia de capacidades.

Entretanto, em suas obras, Schumpeter considera a inovação tecnológica como uma variável exógena ao modelo explicativo, assim como fatores sócio-institucionais mais amplos. Carlota Perez (2007) busca avançar na compreensão do papel das instituições e da inovação como variável endógena ao modelo defendendo que o fator causador do caráter cíclico do capitalismo é oriundo do efeito assimétrico das revoluções tecnológicas sobre as esferas econômicas (mais mutáveis) e sócio-institucionais (mais difíceis de modificar). Ou seja, existe oposição entre o dinamismo da tecnologia e o caráter conservador e estável das instituições. Assim, para lidar com as características dos ciclos tecnológicos de longo prazo, "ela cria o conceito de 'paradigma técnico-econômico', que abarca as duas dimensões da mudança (técnico-econômica e sócio-institucionais) e cuja criação depende do ajuste do marco institucional à nova realidade tecnológica" (Muller 2009, 43). Na tabela abaixo, podemos verificar os cinco paradigmas técnico-econômicos de Perez e os países que lideraram o ciclo tecnológico. 
Tabela 1 - Paradigmas Técnico-econômicos de Carlota Perez

\begin{tabular}{|c|c|c|c|c|}
\hline \multicolumn{5}{|c|}{ Os "big bangs" das ondas técnico-econômicas de Carlota Perez (2002) } \\
\hline $\begin{array}{l}\text { Revolucão } \\
\text { Tecnológica }\end{array}$ & $\begin{array}{l}\text { Nome popular do } \\
\text { periodo }\end{array}$ & $\begin{array}{l}\text { Pais ou Países } \\
\text { central(is) }\end{array}$ & Big Bang & Ano \\
\hline Primeira & A "Revolução Industrial" & Grã Bretanha (GB) & $\begin{array}{l}\text { Moinho de } \\
\text { Arkwright }\end{array}$ & 1771 \\
\hline Segunda & $\begin{array}{l}\text { Era do Vapor e das } \\
\text { Ferrovias }\end{array}$ & $\begin{array}{l}\text { GB (espalhando para o } \\
\text { continente e para os } \\
\text { Estados Unidos) }\end{array}$ & $\begin{array}{l}\text { Teste da locomotiva } \\
\text { "Rocket" }\end{array}$ & 1829 \\
\hline Terceira & $\begin{array}{l}\text { Era do aço, eletricidade e } \\
\text { engenharia pesada }\end{array}$ & $\begin{array}{l}\text { EUA e Alemanha } \\
\text { ultrapassando a GB }\end{array}$ & $\begin{array}{l}\text { Planta produtora de } \\
\text { aço Bessemer de } \\
\text { Carnegie }\end{array}$ & 1875 \\
\hline Quarta & $\begin{array}{l}\text { Era do petrólco, do } \\
\text { automóvel e da produção } \\
\text { em massa }\end{array}$ & $\begin{array}{l}\text { EUA, concorrência } \\
\text { alemã e expandindo-se } \\
\text { pelo mundo }\end{array}$ & $\begin{array}{l}\text { Lançamento do } \\
\text { modelo Ford-T }\end{array}$ & 1908 \\
\hline Quinta & $\begin{array}{l}\text { Era da Informaçào e das } \\
\text { Telecomunicaçōes }\end{array}$ & $\begin{array}{l}\text { EUA, espalhando-se } \\
\text { pela Europa e pela } \\
\text { Ásia }\end{array}$ & $\begin{array}{l}\text { Lançamento do } \\
\text { primeiro microchip } \\
\text { comercial da Intel }\end{array}$ & 1971 \\
\hline
\end{tabular}

Fonte: Bueno (2009) baseado em Perez (2002).

A capacidade de entronizar as decisões relativas à inovação tecnológica é parte fundamental do processo de desenvolvimento e da inserção internacional de um país. Vale apontar o caso brasileiro, conforme Muller (2009, 43),

o paradigma do aço e da eletricidade, que começa em I875, corresponde à entronização brasileira da siderurgia. O do petróleo e do automóvel, que começou em I908, corresponde à entronização da química fina no Brasil a partir dos anos I950. Desde I97I, esse desafio estratégico de desenvolvimento se insere no paradigma da informação e da telecomunicação, o que abarca chips, microeletrônica, computadores, softwares, fibra-ótica, semi e supercondutores, etc. Tal contexto corresponde, assim, ao domínio da digitalização, posto que o computador digital é o "nó" que serve de núcleo às redes de comunicação.

Para que um país não fique à margem do desenvolvimento dos paradigmas técnico-econômicos que dominam a dinâmica internacional, é necessário criar mecanismos institucionais que deem conta dos desafios econômicos. É nesse sentido que o conceito de "Centro de Decisão" de Celso Furtado (I962), um dos fundadores da escola cepalina, torna-se fundamental para compreender o processo de endogeneização do desenvolvimento econômico e tecnológico. Essa ideia é compreendida como a capacidade de o Estado gerir, da forma como lhe convier, o seu próprio desenvolvimento econômico a partir 
do controle das tecnologias e técnicas produtivas nucleadoras de determinada etapa do desenvolvimento econômico. Ou seja, relaciona-se com os mecanismos político-institucionais e sociais criados para consolidar a capacidade de um país em tomar decisões relativas ao seu próprio desenvolvimento em um novo paradigma técnico-econômico.

Conforme coloca Oliveira (2012, 29), "o controle dos processos decisórios na esfera nacional se contrapõe aos casos em que as decisões referentes à economia e às atividades produtivas ocorrem no exterior, ou seja, são decisões tomadas por atores estrangeiros que não necessariamente compartilham dos interesses e objetivos de desenvolvimento do país". Para um país ser capaz de planejar e executar um projeto nacional de desenvolvimento e, portanto, atingir certo grau de autonomia estratégica que permita uma inserção internacional soberana, é preciso nacionalizar os Centros de Decisão do atual paradigma técnico-econômico atual, qual seja, a digitalização.

É dentro da perspectiva do domínio do Centro de Decisão da digitalização que a modernização das Forças Armadas através, em partes, da indústria de defesa nacional é estratégica e estruturante, tanto para a soberania de um país quanto para seu desenvolvimento econômico. Dado que a defesa é um bem público que o Estado tem como função fundamental prover e, portanto, encontra legitimidade suficiente para agir estrategicamente a partir da promoção de políticas robustas, ela pode ser utilizada como forma de entronizar o Centro de Decisão da digitalização. Concordamos com Martins (2008, I5) quando o autor coloca que

capacidades militares digitais no estado da arte (o que é feito através da aquisição de sistemas, transferências e nacionalização de tecnologia) reestruturam o Estado fisicamente e permitem a recuperação do centro de decisão econômica. A digitalização equivale nos dias de hoje para a estratégia nacional o que, ao seu tempo, foi a aquisição do centro de decisão da siderurgia, da química fina, e da energia nuclear. Em síntese, a recuperação da capacidade operacional das forças armadas importa para todo o desenvolvimento socioeconômico. A digitalização acarreta uma crescente instabilidade do sistema internacional que, ao criar ameaças de guerra local, engendra como resposta sistêmica investimentos militares. Se, ao invés de adquirir material bélico no exterior, optar-se pela produção nativa, estes investimentos podem dotar as potências regionais do centro de decisão (semicondutores e supercondutores) que são o núcleo da economia contemporânea.

A indústria de defesa pode ser considerada um dos pilares para a entronização do Centro de Decisão da digitalização a partir de três pontos centrais. Primeiramente, as tecnologias duais são preponderantes na dinâmica 
da digitalização, dada a presença de semicondutores e supercondutores na maior parte dos equipamentos civis e dos sistemas de armas. A boa sinergia entre tecnologias de uso dual permite a diluição de investimentos em pesquisas entre áreas civis e militares que aproximem o país do controle dos processos produtivos das tecnologias nucleares do Centro de Decisão.

Em segundo lugar, muitas tecnologias críticas da digitalização são negadas por quem as domina, tanto para fins civis quanto militares. As tecnologias espaciais são um exemplo claro, pois é comum que subsistemas e componentes que irão compor um projeto espacial com fins civis (ex.: comunicação comercial, sensoriamento remoto e rastreamento) tenha sua venda proibida com justificativas de segurança nacional. Assim, o cerceamento tecnológico sob a perspectiva militar também impacta nos setores civis. Logo, as medidas que o Estado pode tomar para superar o cerceamento tecnológico impactarão nas duas dimensões. Uma vez que o Estado consegue gerenciar o cerceamento tecnológico a partir de parcerias internacionais, as especificidades da defesa tornam possíveis determinados arranjos negociais que não seriam possíveis em setores comerciais. Conforme coloca Brick (2016), "os investimentos em defesa são imunes a retaliações comerciais no âmbito da OMC (Organização Mundial do Comércio), ao contrário de outros investimentos governamentais em P\&D"7.

Em terceiro lugar, o Estado possui legitimidade para atuar enquanto promotor do desenvolvimento desta indústria. Em casos históricos, o Estado exerceu forte papel indutor da indústria de defesa sem sofrer tantos questionamentos pela sua intervenção econômica, especialmente no que se refere ao estabelecimento da infraestrutura de Ciência, Tecnologia e Inovação (CT\&I) necessária para o seu desenvolvimento. Mariana Mazzucato (20I4) argumenta que a experiência estadunidense do desenvolvimento tecnológico para vencer guerras só foi possível graças a iniciativas estatais. Além disso, conforme Brick (20I6), as políticas industriais e tecnológicas específicas para a defesa

não oneram a economia do país porque todo o custo é ıo०\% dimensionado e contido no orçamento de defesa. A sociedade não paga por isso como nas políticas passadas de reserva de mercado como as de informática e conteúdo local na indústria de petróleo, que geram custos para os consumidores, aumentos de custo e atrasos em investimentos, sem desenvolver e criar uma capacidade industrial e tecnológica para o país ${ }^{8}$.

7 Entrevista de 26 de julho de 2016 , disponível em: http://defesaeseguranca.com.br/entrevista-engenheiro-detalha-estudo-sobre-industria-de-defesa/.

8 Entrevista de 26 de julho de 2016 , disponível em: http://defesaeseguranca.com.br/entrevista-engenheiro-detalha-estudo-sobre-industria-de-defesa/. 
Dessa forma, dado que "o desenvolvimento de uma defesa nacional forte depende de uma estrutura científico-tecnológica nacional robusta, e o fortalecimento desta estrutura depende da indução estatal, cabe ao Estado a responsabilidade maior pelo desenvolvimento da CT\&I voltada para a defesa e, consequentemente, pelo fortalecimento da BID [Base Industrial de Defesa]" (Andrade e Franco 2016, I8).

Portanto, consideramos que os impactos da Indústria de Defesa no desenvolvimento econômico e tecnológico não podem ser plenamente compreendidos a partir de concepções que foquem na relação causal ou correlação entre gastos militares e crescimento econômico de forma estrita, mas sim como uma variável central no controle dos Centros de Decisão referentes aos paradigmas técnico-econômicos que regem as transições tecnológicas de longo prazo.

\section{Indústria de defesa e Política Industrial}

Para que a indústria de defesa exerça seu papel nos esforços de endogeneização de centros de decisão econômicos no país, é preciso que o desenvolvimento industrial e tecnológico deste setor esteja inserido coerentemente na Grande Estratégia9 ${ }^{9}$ do país. Além da aplicação dos recursos de poder, a Grande Estratégia se ocupa com o desenvolvimento e com a alocação destes recursos (Layton 20I2). Nesse sentido, a capacidade de dominar tecnologias críticas da era da digitalização na BID é fundamental para garantir a manutenção do poder militar e para aspirar posições de liderança no sistema internacional.

O cenário internacional atual não manteve as expectativas do fim da Guerra Fria, onde se imaginava que se haveria alcançado um modelo duradouro de promoção da paz a partir da hegemonia de uma superpotência. A crescente polarização do sistema internacional (Huntington I999; Amin 2006) tem levado à tensão entre Estados Unidos, Rússia, China e algumas potências regionais a novos teatros e esferas de conflito, disputando posições estratégicas ao redor do mundo e, sistematicamente, fazendo "uso de seu poderio militar como instrumento de pressão política, agora reforçado pelas novas tecnologias cibernéticas e aeroespaciais" (Filho e Moraes 20I2, I4).

Nesse cenário instável, a digitalização das tecnologias militares e a modernização das Forças Armadas do mundo trazem desafios aos países que desejam manter uma capacidade autônoma de manutenção de soberania e

9 Sobre Grande Estratégia, ver Gray (20II); Brands (20II); Hoffman (20I4).

150 Austral: Revista Brasileira de Estratégia e Relações Internacionais v.6, n.11, Jan./Jun. 2017 
que buscam inserir-se estrategicamente na ordem internacional (Martins 2008). Conforme colocam Filho e Moraes (2012, I5),

[é] justamente no campo tecnológico que se percebem as maiores transformações dos exércitos. O poderio militar assentado sobre a quantidade de meios e efetivos cede cada vez mais espaço a estruturas de defesa menores e mais flexíveis, mas com elevada capacidade operacional, graças ao contínuo aprimoramento dos meios de combate. Estas novas configurações demandam, por sua vez, investimentos cada vez maiores em tecnologia e na preparação de recursos humanos capacitados a operar sistemas integrados de defesa. Também se intensifica o processo de combinação e interoperabilidade, ensejando a necessidade de convergência dos planos e doutrinas das três forças (Exército, Marinha e Aeronáutica). Por fim, os frequentes ataques cibernéticos, desestabilizando sistemas de controle civis e militares de diversas nações, bem como os riscos representados pela "militarização do espaço" no contexto de um mundo cada vez mais dependente de satélites, apontam não apenas ameaças, mas também caminhos necessários para o progresso futuro da tecnologia militar.

O desenvolvimento de tecnologia militar e a capacidade de industrializá-la ao ponto de mobilizar meios materiais suficientes para responder a uma ameaça externa em conflitos de média e longa duração é essencial para a inserção estratégica internacional de um país que pretende se colocar como protagonista mundial. O Poder Militar só ganha concretude em sua base material, que é construída e/ou mantida pela Base Industrial de Defesa. O fortalecimento de uma Base Industrial de Defesa (BID) está intrinsecamente ligado à capacidade de defesa autônoma por parte de um Estado, pois ao possuir as instalações industriais e conhecimentos tecnológicos capazes de efetivamente produzir e utilizar os bens necessários para a Defesa Nacional, assegura-se elemento fundamental para a capacidade de mobilização e resposta. Dessa forma, a BID acaba sendo o pilar central garantidor de uma diplomacia ativa e soberana. Conforme aponta Melo $(2015,26)$,

uma política externa independente e universal tem por complemento necessário uma política de defesa robusta... e elemento essencial de uma política de defesa robusta é uma Base Industrial e Tecnológica de Defesa capaz de aparelhar as Forças Armadas. Sua estruturação e fortalecimento constituem uma prioridade estratégica para um país como o Brasil, que, além de possuir considerável patrimônio de recursos naturais estratégicos que precisa proteger, está buscando uma inserção ativa no cenário político e econômico internacional.

A constituição de uma BID representa grande desafio para países 
emergentes, dado que Ciência, Tecnologia e Desenvolvimento é uma arena de disputa de poder no sistema internacional, especialmente quando se refere às tecnologias militares, um reflexo de um mercado de defesa fechado e competitivo, restritivo às transferências de tecnologia (Moreira 20I6). Dado o caráter de tecnologia sensível ${ }^{\text {1o }}$ que a tecnologia militar intrinsecamente possui, o cerceamento tecnológico ${ }^{\mathrm{II}}$ é uma prática usual no comércio internacional de sistemas militares. Dessa forma, é preciso que o Estado considere em sua política externa, em sua política de defesa e em sua política de desenvolvimento (especialmente a política industrial), formas de lidar com os desafios relativos ao desenvolvimento tecnológico e à industrialização de soluções militares a partir de uma indústria de defesa nacional robusta e consolidada de forma a diminuir sua dependência externa em tecnologias sensíveis. De acordo com Brick (20I4),

[m]odernos produtos de defesa sofrem severas restrições para aquisição no mercado internacional e, quando disponíveis, nunca correspondem ao que existe de mais atual e/ou eficaz para enfrentar as ameaças contemporâneas. Assim, para garantir a sua soberania e os seus interesses, nenhum país, que pretenda ser um ator relevante no sistema internacional, poderá prescindir de um complexo tecnológico-científico-industrial capaz de suprir as suas FFAA com os produtos de defesa necessários para enfrentar ameaças que possam vir a ser apresentadas por quaisquer outros países.

Portanto, consideramos que a Indústria de Defesa é estratégica para qualquer país que deseja manter sua soberania e sua autonomia no século XXI e é variável-chave para a composição do Poder Nacional (Tellis et al. 2000). Assim, "o apoio estatal às indústrias de defesa se justifica, do ponto de

Io Segundo Longo (20II), tecnologia sensível refere-se às tecnologias de natureza civil ou militar cujo determinado grupo de países ou país perceba que não deve ser repassada, durante um período não determinado, declaradamente por razões de segurança nacional.

II Coloca Amarante (20I3, 80-82) que “a prática do cerceamento tecnológico (...) é um conjunto de medidas judiciais tomadas normalmente por Estados desenvolvidos contra Estados em desenvolvimento ou emergentes, no sentido de evitar o acesso a tecnologias sensíveis. (...) A política de não obtenção, pura e simples, impede o acesso a conhecimentos sensíveis, já dominadas e exploradas por um seleto grupo de países. Trata-se de um bloqueio que afasta os necessitados das benesses da ciência, tecnologia e inovação, provocando o alargamento do hiato tecnológico entre os que sabem e os que não sabem. Resumindo e enfatizando, os países líderes no desenvolvimento científico, tecnológico e inovativo têm praticado o cerceamento explícito de terceiros ao acesso às tecnologias que, unilateralmente, consideram sensíveis. Exemplificando, vejam-se as áreas de estudo consideradas sensíveis pelos Estados Unidos, constantes da Technology Alert List (TAL), emitida pelo Departamento de Estado dos EUA. Quando violado, o cerceamento pode ou não ser acompanhado por retaliações, principalmente de ordem econômica". 
vista estratégico, porque uma BID desenvolvida possibilita ao Estado o domínio de capacidades tecnológicas próprias, conferindo-lhe um poder adicional de peso perante o sistema internacional" (Mota e Rodrigues 20I2, 3).

A BID também é importante em seus aspectos de estruturação econômica e tecnológica "que estão relacionados ao domínio de tecnologias sensíveis, muitas com caráter dual, e à geração de inovação, de empregos de alta qualificação e de exportações de elevado valor agregado" (Melo 20I5, 26). Conforme já apontamos anteriormente, a BID é uma estratégia possível para a endogenização do Centro de Decisão da era da digitalização.

Para o Estado atuar de maneira transformadora no tecido industrial de um país, é condição necessária o desenvolvimento de uma política industrial robusta. É nesse sentido que as políticas públicas voltadas para o desenvolvimento da BID precisam estar alinhadas com a política industrial ampla do Estado. A política industrial é um instrumento de intervenção econômica do Estado, cujo objetivo é alterar o status quo do mercado, conformando o comportamento dos atores econômicos a partir de mecanismos de incentivo, condicionalidade, restrições e proibições para o fim desejado pelos formuladores da política.

Shapiro $(2014,242)$ aponta que há duas principais abordagens que informam a lógica da Política de Desenvolvimento e a ação regulatória das políticas industriais: i) a visão das falhas de mercado, cujos atributos principais são a hipótese da primazia de mercado e a avaliação estática de seu processo de concorrência, e o tipo de intervenção que o Estado pode realizar é a correção das falhas horizontalmente (sem a escolha de setores) para nivelar as condições de mercado e permitir que os agentes econômicos maximizem as eficiências existentes; e ii) a visão estruturalista-evolucionista, em que o Estado pode instituir e conformar o ambiente econômico e os seus instrumentos servem para "alterar a alocação econômica existente em direção a outro padrão de especialização produtiva, mais tendente a incorporar a inovação e o progresso técnico" (Ibidem, 243), ou seja, a política industrial estrutural-evolucionista procura priorizar setores capazes de difundir inovação, propositalmente criando uma assimetria economia entre diferentes setores.

Cimoli et al. $(2007,68)$ apontam que as políticas industriais (de tipo estrutural-evolucionista) e as instituições desenvolvidas para conduzi-las afetam conjuntamente

i) as capacidades tecnológicas de organizações individuais e corporativas, e o ritmo em que elas conseguem aprender; ii) os sinais econômicos percebidos por elas (incluindo, naturalmente, os sinais de lucratividade e os custos de oportunidade percebidos); iii) as formas como elas interagem uma com 
as outras e com outras instituições não-mercantis (como agências públicas, bancos de desenvolvimento, entidades de treinamento e pesquisa, etc.).

Concordamos com os autores quando afirmam que

Ocorre que todos os principais países desenvolvidos possuem atualmente graus de intervenção relativamente altos - sejam eles conscientemente concebidos como políticas industriais ou não - os quais afetam todas as variáveis acima indicadas. E isto se aplica, ainda mais, ao período em que os países desenvolvidos de hoje estavam procurando emparelhar-se ao líder internacional da época. O que primordialmente diferencia os vários países são os instrumentos, os arranjos institucionais e a filosofia da intervenção (Cimoli et al. 2007, 68).

Assim, para induzir uma transformação estrutural e voltada para a inovação, especialmente em um setor tão estratégico e competitivo e que requer inovação constante como o da indústria de defesa, é condição necessária uma política industrial estrutural-evolucionista estabelecer instrumentos e arranjos institucionais que estejam alinhados com esse tipo de política industrial. Para implementar e executar uma política industrial de defesa robusta é necessário se criar as condições políticas e institucionais para coordenar e processar os vários atores e interesses envolvidos na condução da política pública (Evans I995; Rodrik 2004). Portanto, a estratégia de endogeneização da digitalização através da indústria de defesa necessita de uma ação enfática do Estado através de políticas industriais que estabeleçam diretrizes, instituições e instrumentos voltados para o fomento do setor.

\section{Conclusão}

Este artigo teve como objetivo principal discutir o debate teórico que envolve a relação entre defesa e desenvolvimento. As implicações deste debate se materializam em posicionamentos ideológicos e em escolhas de políticas públicas que influenciam os gastos públicos com defesa e a aquisição de novos sistemas. Dessa forma, buscou-se enfatizar a abordagem que aponta que gastos militares estão mais relacionados com o desenvolvimento tecnológico do que com o crescimento econômico.

A promoção da indústria de defesa é uma escolha estratégica viável para que um país consiga endogeneizar as tecnologias da digitalização e, assim, nacionalizar os meios necessários para ser protagonista de seu próprio 
desenvolvimento. O Estado, enquanto monopolizador legítimo do uso da força, conta com legitimidade para estabelecer políticas robustas que garantem o fornecimento material para sua defesa. Partindo-se dessa premissa, pode ser através das políticas de desenvolvimento da indústria de defesa que o Estado se capacita para intervir no tecido industrial e tecnológico do país sem ser acusado de excessivo intervencionismo.

Portanto, a formulação e implementação de políticas industriais voltadas para o fortalecimento da indústria de defesa são instrumentos para o desenvolvimento tecnológico do país e com potencial de implementar tecnologias críticas para transformações significativas no tecido industrial. Sendo assim, é fundamental, para o avanço dos estudos sobre a indústria de defesa, pesquisas que se dediquem a compreender o desenho das políticas industriais e os arranjos institucionais estruturados para formulá-las e implementá-las.

\section{REFERÊNCIAS}

Amarante, José Carlos Albano. 2013. Processos de Obtenção de Tecnologia Militar. Brasília: IPEA.

Amin, Samir. 2006. Beyond US hegemony? Assessing the prospects for a multipolar world. London: Zed Books.

Andrade, Israel de Oliveira, and Luiz Gustavo Aversa Franco. 20ı6. Desnacionalização da Indústria de Defesa no Brasil: Implicações em aspectos de autonomia científico-tecnológica e soluções a partir da experiência internacional. Brasília: IPEA.

Biswas, Basudeb, and Rati Ram. I986. "Military Expenditures and Economic Growth in Less Developed Countries: An Augmented Model and Further Evidence". Economic Development and Cultural Change 34 (2): 36I72.

Bohn, Eduardo Cesar. 20I4. Indústria de Defesa e Processos de Aquisição no Brasil: uma sugestão de debate baseado em modelos para países em desenvolvimento. Porto Alegre: UFRGS.

Brands, Hal. 20II. What Good is Grand Strategy? Power and Purpose in American Statecraft from Harry S. Truman to George W. Bush. Ithaca: Cornell University Press.

Brick, Eduardo Siqueira. 20I4. "Uma Estratégia para o Desenvolvimento e a Sustentação da Base Logística de Defesa Brasileira”. Relatório de Pesquisa em Engenharia de Produção Série D I4 (2): 12-20. 20I6. Engenharia e Defesa: uma visão de acadêmicos de Engenharia 
- sugestões para a revisão da Política (PND) e da Estratégia Nacional de Defesa (END). Rio de Janeiro: Academia Nacional de Engenharia. http://anebrasil.org.br/wp-content/uploads/images/pdf/opinioes/ visao-academicos-engenharia.pdf.

Buzan, Barry, and Eric Herring. 1998. The Arms Dynamics in World Politics. Boulder: Lynne Rienner.

Cimoli, Mario, Giovanni Dosi, Richard R. Nelson, and Joseph Stiglitz. 2007. "Instituições e políticas moldando o desenvolvimento industrial: uma nota introdutória". Revista Brasileira de Inovação 6 (I): 55-85.

Dagnino, Renato Peixoto. I989. A Indústria de armamentos brasileira: uma tentativa de avaliação. I989. Campinas: Universidade Estadual de Campinas.

. 20Io. A indústria de defesa no governo Lula. São Paulo: Expressão Popular.

Deger, Saadet. I986. Military Expenditure in Third World Countries: The Economic Effects. London: Routledge.

Deger, Saadet, and Ron Smith. 1983. "Military Expenditure and Growth in Less Developed Countries". Journal Conflict Resolution 27: 335-353.

Dreze, Jean. 2006. "Military Expenditure and Economic Growth". In The Elgar Companion to Development Studies. Cheltenham: Edward Elgar.

Dunnes, Paul e Eftychia Nikolaidou. 20II. "Defence Spending and Economic Growth in the EU 15". In Fourteenth International Conference on Economics and Security. Izmir: Izmir University of Economics.

Evans, Peter. I995. Embedded autonomy: states and industrial transformation. New Jersey: Princeton University Press.

Faini, Riccardo, Patricia Annez, and Lance Taylor. I984. "Defence Spending, Economic Structure, and Growth Evidence among Countries and Over Time". Economic Development and Cultural Change 32 (3): $487-498$.

Ferder, Gershon. I983. "On Exports and Economic Growth". Journal of Development Economics I2 (I-2): 59-83.

Filho, Edison Benedito da Silva, and Rodrigo Fracalossi de Moraes. 2012. Defesa Nacional para o Século XXI: Política Internacional, Estratégia e Tecnologia Militar. Brasília: IPEA.

Hartley, Keith, and Todd Sandler. I995. Handbook of Defense Economics. Amsterdam: North Holland.

Huntington, Samuel. I999. “The Lonely Superpower”. Foreign Affairs. March/ April. 
Layton, Peter. 20I2. "The Idea of grand strategy". Rusi Journal I57 (4): 56-6I. Lebovic, James, and Ashfaq Ishaq. I987. "Military burden, security needs, and economic growth in the Middle East". Journal of Conflict Resolution 3I (I): 106-3.

Longo, Waldimir Pirró. 20II. "Indústria de defesa: pesquisa, desenvolvimento experimental e engenharia”. Revista da Escola Superior de Guerra 25 (52).

Martins, José Miguel Quedi. 2008. "Digitalização e guerra local: fatores do equilibrio internacional". PhD thesis, Federal University of Rio Grande do Sul.

Matthews, Ron, and Curie Maharani. "The Defense Iron Triangle Revisited". In Modern Defense Industry: political, economic and Technological issues. Santa Barbara: Praeger Security International.

Mello, Regine de. 20I5. Indústria de Defesa e Desenvolvimento Estratégico: estudo comparado França-Brasil. Brasília: FUNAG.

Moreira, William de Souza. 20ı6. "Tecnologia, Estratégia e Planejamento de Defesa”. In IX Encontro da Associação Brasileira de Estudos de Defesa. Florianópolis: Anais IX ENABED.

Mota, Rui Martins, and Gustavo Assad de Praga Rodrigues. 20I2. "Debatendo o Fortalecimento da BID do Brasil". In VI Encontro Nacional da Associação Brasileira de Estudos de Defesa and I Encontro Sul-Americano de Defesa. São Paulo: Anais do VI ENABED.

Mueller, Michael, and H. Sonmez Atesoglu. I993. "Defense spending, technological change, and economic growth in the United States". Defence Economics 4: 259-269.

Muller, Gustavo Gayger. 2009. "Parceria Estratégica Brasil-França: Perspectivas para o Desenvolvimento de Blindados". Undergraduate final paper, Federal University of Rio Grande do Sul.

Oliveira, Lucas Kerr de. 20I2. "Energia como recurso de poder na política internacional: geopolítica, estratégia e o papel do Centro de Decisão Energética”. $\mathrm{PhD}$ thesis, Federal University of Rio Grande do Sul.

Porcile, Gabriel, Luis Alberto Esteves, and Fabio Doria Scatolin. 2006. "Tecnologia e desenvolvimento econômico". In Economia da Inovação Tecnológica. São Paulo: HUCITEC.

Ram, Rati. 1986. "Government Size and Economic Growth: A new framework and Some Evidence from Cross-Section and Time-Series Data". American Economic Review 76 (I): I9I-203.

Rodrik, Dani. 2004. "Industrial Policy for the Twenty-First Century". Working Paper prepared for UNIDO. https://www.sss.ias.edu/files/pdfs/Ro- 
drik/Research/industrial-policy-twenty-first-century.pdf.

Schumpeter, Joseph. I96r. Imperialismo e classes sociais. Rio de Janeiro: Zahar. Skinner, Quentin. I969. "Meaning and Understanding in the History of Ideas". History and Theory 8 (I): 3-53.

Smith, Ron, and Paul Dunne. 1994. "Is Military Spending A Burden?: A Marxo-Marginalist Response to Pivetti”. Cambridge Journal of Economics I8: 515-527.

Souza, Nali de Jesus de. 20II. Desenvolvimento econômico. São Paulo: Atlas.

Tekeoglu, Ertugrul. 2008. Defense Expenditure and Economic Growth: Empirical Study on the Case of Turkey. Monterey: Naval Postgraduate School.

Walsh, Kathlenn A. 2009. "The Role, Promise, and Challenges of Dual-Use Technologies in National Defense". In The Modern Defense Industry: political, economic and Technological issues. Santa Barbara: Praeger Security International.

\section{RESUMO}

Este artigo tem como objetivo principal expor o debate em torno da relação entre gastos militares e desenvolvimento econômico, assim como entre indústria de defesa e desenvolvimento tecnológico. Com este intuito, exploramos a literatura desde a escola clássica da economia, passando por autores marxistas, cepalinos, schumpeterianos e neoclássicos. Argumentamos neste artigo que o fortalecimento da indústria de defesa, através de política industrial robusta e focada, é uma estratégia viável para a endogeneização de tecnologias críticas centrais para o domínio do paradigma de desenvolvimento da digitalização. Esta estratégia demanda a construção de uma política industrial robusta voltada para o desenvolvimento e fortalecimento da indústria de defesa nacional. Para tanto, é necessário avançar na agenda de pesquisa de arranjos institucionais e governança voltados a este setor.

\section{PALAVRAS-CHAVE}

Indústria de defesa; Desenvolvimento; Política Industrial; Gastos Militares; Economia da Defesa.

Recebido em 12 de julho de 2017. Aprovado em 16 de agosto de 2017. 